\title{
Root canal treatment of permanent mandibular first molar with six root canals: a rare case
}

\author{
Ersan Çiçek, ${ }^{1}$ Neslihan Yılmaz, ${ }^{1}$ Murat İçen ${ }^{2}$ \\ 'Department of Endodontics, Faculty of Dentistry, Bülent Ecevit University, Zonguldak, Turkey \\ ${ }^{2}$ Department of Oral Radiology, Faculty of Dentistry, Bülent Ecevit University, Zonguldak, Turkey
}

\begin{abstract}
This case report aims to present the management of a mandibular first molar with six root canals, four in mesial and two in distal root. A 16-year-old male patient who has suffered from localized dull pain in his lower left posterior region for a long time was referred to the endodontic clinic. On clinical examination, neither caries lesion nor restoration was observed on the mandibular molar teeth; but the occlusal surface of the teeth had pathologic attrition. The mandibular and maxillary molars were tender to percussion due to bruxism, but there was no tenderness towards palpation. All of the molars revealed normal responses to the vitality tests. It was suggested that he should use the night-guard against bruxism. After three months, his pain almost completely relieved, but the percussion of the left mandibular molar was still going on. After access cavity preparation, careful examination of the pulp chamber floor with dental loupe and endodontic explorer (DG 16 probe) showed six canal orifices, four of mesially and two of distally. CBCT scan was performed in order to confirm the presence of six canals. Following one year, it was observed that he had no pain.
\end{abstract}

Keywords: $\mathrm{CBCT}$; root canal treatment; unusual canal morphology.

The awareness of internal dental morphology is an excessively critical step in management of endodontic therapy. [1] The mandibular first molar, the earliest permanent tooth to erupt is assumed to be the tooth that mostly creates need for root canal treatment. The most common root canal morphology of the mandibular first molar is the presence of two canals in the mesial root and one or two canals in the distal root. ${ }^{[2]}$ However, the literature indicates a number of case reports on the anatomic alterations and the variations related to the mandibular first molars. Amazingly, Reeh ${ }^{[3]}$ reported a case with seven canals, involving four canals in the mesial root and three canals in the distal root.
The knowledge of such anatomic variations of root and root canals is an essential aspect in managing the degree of success of root canal treatment. Without an efficient exploration, a canal could be left unprepared and inaccurate disinfection of root canal system is inevitable, so the endodontic therapy may result in failure. ${ }^{[4]}$

This case report aims to present the management of a mandibular first molar with six root canals, four of which are placed in mesial and two of which are placed in distal root. Moreover, this case report highlights the usage of Cone Beam Computed Tomography (CBCT) as a diagnostic tool in endodontic practice.

Correspondence: Dr. Ersan Çiçek. Bülent Ecevit Üniversitesi, Diş Hekimliği Fakültesi,

Endodonti Anabilim Dalı, Zonguldak, Turkey.

Tel: +90372 - 2613640 e-mail: ersancicek@beun.edu.tr

Submitted: May 11, 2015 Accepted: May 23, 2015

(C2016 Turkish Endodontic Society 


\section{Case report}

A 16-year-old male patient who has suffered from localized dull pain in his lower left posterior region for a long time was referred to the endodontic clinic. His medical history showed that he has a Familial Mediterranean Fever disease. On clinical examination, neither caries lesion nor restoration was observed on the mandibular molar teeth; but the occlusal surface of the teeth had pathologic attrition. The mandibular and maxillary molars were tender to percussion due to bruxism, but there was no tenderness to palpation. A panoramic radiograph was taken and no radiolucency was detected around the related teeth. All of the molars revealed normal responses to the vitality tests (thermal and electric pulp test). It was suggested that he should use the night guard against bruxism. After three months, his pain almost completely relieved, but the tenderness to the percussion of the left mandibular molar was still persisted.
Access cavity preparation was performed under local anesthesia and the tooth was isolated with rubber dam. The pulp chamber was flushed with $2.5 \%$ sodium hypochlorite $(\mathrm{NaOCl})$ to remove the debris. Careful examination of the pulp chamber floor with dental loupe (Heine, Herrsching, Germany) and endodontic explorer (DG 16 probe) showed six canal orifices, four of which were placed mesially and two of which were placed distally. Glide path and apical patency were achieved by using number $8 \mathrm{~K}$ file (Mani, Inc. Japan). Working length was determined with electronic apex locator (Root ZX) (J. Morita Corp., Kyoto, Japan). CBCT scan was performed in order to confirm the presence of six canals in the related tooth (Figures la and $b)$.

Cleaning and shaping was performed using a crown down preparation with the rotary ProTaper Universal instruments (Maillefer, Dentsply, Ballaigues, Switzerland)
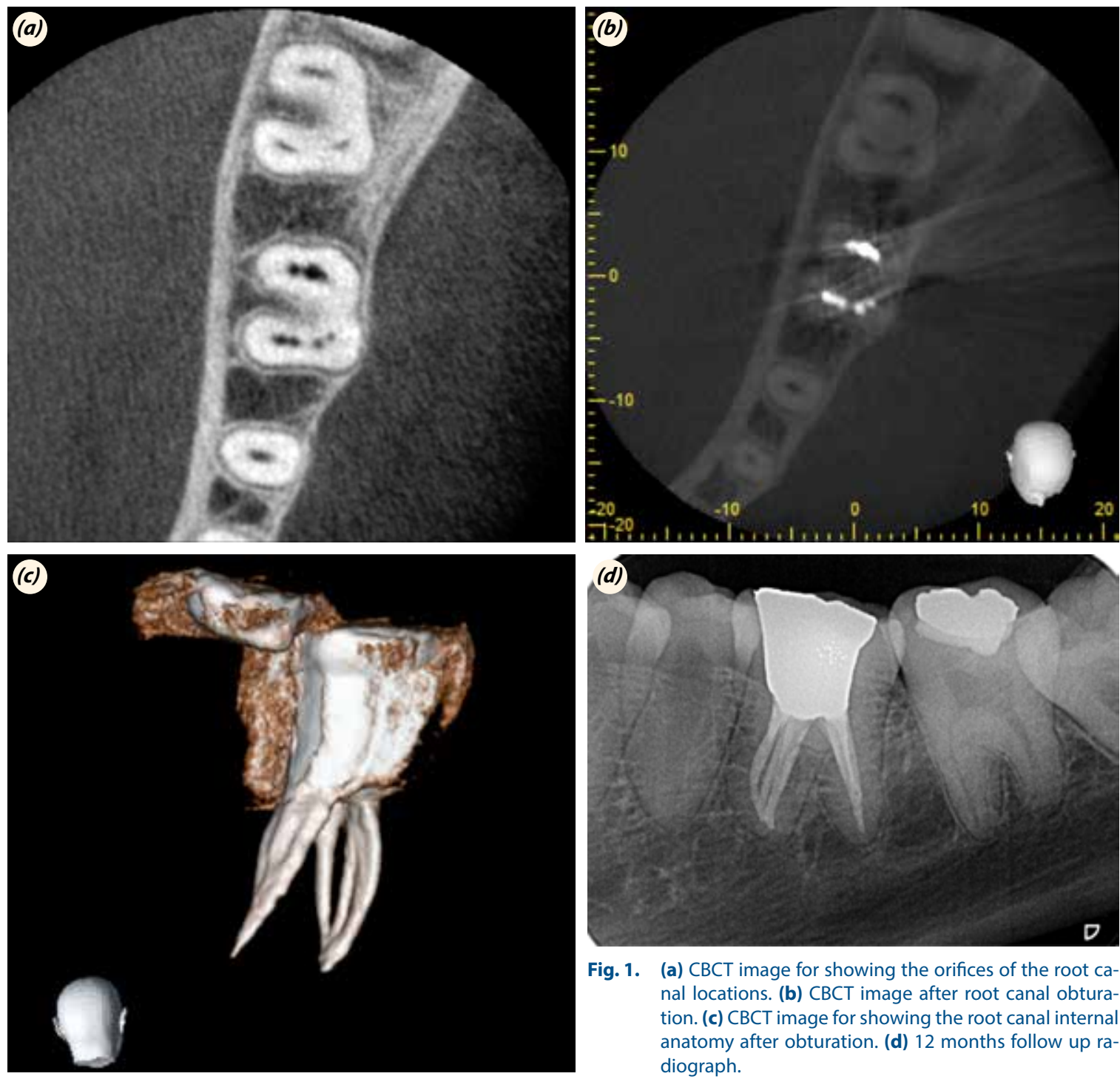

Fig. 1. (a) $C B C T$ image for showing the orifices of the root canal locations. (b) CBCT image after root canal obturation. (c) CBCT image for showing the root canal internal anatomy after obturation. (d) 12 months follow up radiograph. 
from SX to $\mathrm{F} 2$ with copious irrigation $(2.5 \% \mathrm{NaOCl})$. The final irrigation of the canals was done with $5 \% \mathrm{NaOCl}$ for 3 minutes, followed by 17\% EDTA solution for 1 minute. After the canals were dried with paper points, guttapercha cones were infixed in dried root canals to prove the working lengths. The obturation was carried out with Protaper gutta-percha cones (Maillefer, Dentsply, Ballaigues, Switzerland) and AH26 (Dentsply De Trey, Konstanz, Germany) root canal sealer. Postoperative intraoral periapical radiograph was taken to assess the quality of obturation. Finally the tooth was restorated with amalgam according to the patient's demand. Following one year, he had no pain and no pathological evidence was determined in radiographic images (Figures $l c$ and $d$ ).

\section{Discussion}

Awareness of abnormal variation of root canal morphology and canal configuration of the teeth plays a critical role in the success of endodontic therapy ${ }^{[5]}$ Many studies have reported the presence of abnormal canals in the mandibular first molar with other three canals in the mesial root as well as in the distal root. ${ }^{[0-8]}$ Furthermore, there is one case report which is related to six canals (two mesial and four distal canals in two distal roots) in literature. ${ }^{[7]}$ However, no case report has presented a mandibular first molar with six root canals as four canals in the mesial root and two canals in the distal root in the literature.

Using magnification and illumination are important to perform a root canal treatment, especially in complicated cases; because, this advanced diagnostic equipment provides more definitive visibility of root canal anatomy. In this case, as we have used dental loupe, no canal was overlooked in related tooth.

Correctness of preoperative radiographs which could be straight or angled is important to show the number of the roots and canals present in a tooth. ${ }^{[9]}$ On the other hand, conventional radiographs are incapable of accomplishing a proper abstraction of the root canal system, since the conventional radiography produces a two-dimensional image out of a three-dimensional object due to the super imposition of the overlying configuration. Therefore, such radiographies are inadequate for imaging the method about the diagnosis of the cases with complex root canal anatomy. Apart from this; CBCT was especially preferred to produce undistorted three dimensional noninvasive data of the root canal configuration. ${ }^{[8]}$ Similarly, in this case, CBCT provided the detection of number and location of the canals.

\section{Conclusion}

Managing the teeth with extraordinary root canal anatomy may not be the only challenge; also, the inadequacy to explore extra canals and improper treatment of the root canals may lead to a failure. To overcome this challenge; all the root canals must be correctly detected by using advanced diagnostic tools like $\mathrm{CBCT}$ or by magnification tools like dental loupes.

Conflics of Interest: No conflicts declared.

\section{References}

1. Favieri A, Barros FG, Campos LC. Root canal therapy of a maxillary first molar with five root canals: case report. Braz Dent J 2006;17:75-8.

2. Vertucci FJ. Root canal anatomy of the human permanent teeth. Oral Surg Oral Med Oral Pathol 1984;58:589-99.

3. Reeh ES. Seven canals in a lower first molar. J Endod 1998;24:497-9.

4. Barbizam JV, Ribeiro RG, Tanomaru Filho M. Unusual anatomy of permanent maxillary molars. J Endod 2004;30:668-71.

5. Adanir $\mathrm{N}$. An unusual maxillary first molar with four roots and six canals: a case report. Aust Dent J 2007;52:333-5.

6. Navarro LF, Luzi A, García AA, García AH. Third canal in the mesial root of permanent mandibular first molars: review of the literature and presentation of 3 clinical reports and 2 in vitro studies. Med Oral Patol Oral Cir Bucal 2007;12:605-9.

7. Hasan M, Rahman M, Saad N. Mandibular first molar with six root canals: a rare entity. BMJ Case Rep 2014.

8. Gupta S, Jaiswal S, Arora R. Endodontic management of permanent mandibular left first molar with six root canals. Contemp Clin Dent 2012;3(Suppl 1):130-3.

9. Theruvil R, Ganesh C, George AC. Endodontic management of a maxillary first and second premolar with three canals. J Conserv Dent 2014;17:88-91. 